\title{
Water Vapor Diffusion Through Soil as Affected by Temperature and Aggregated Size
}

\author{
Jay D. Jabro
}

Published online: 25 September 2008

(C) Springer Science+Business Media B.V. 2008

\section{Erratum to: Transp Porous Med DOI: 10.1007/s11242-008-9267-z}

The first three paragraphs in the introduction section on page 2 should be replaced with the correct ones and read as follows:

The reference below should be added to the references section.

\section{Introduction}

In arid and semiarid regions, water vapor diffusion is an integral component of the total water flux and energy budget in the vadose soil zone in many agricultural, engineering, and meteorological applications because soil water content levels near the soil surface are extremely low (Milly 1984; Parlange et al. 1998).

In agricultural applications, water vapor diffusion through the soil is important because plant seeds can utilize water vapor as a moisture source from the soil environment to germinate (Wuest et al. 1999; Saito et al. 2006).

Understanding water vapor diffusion in the soil for engineering applications is important for the performance evaluation of evapotranspiration covers for waste contaminants in arid and semiarid regions (Scanlon et al. 2005; Saito et al. 2006). In another application, an evaluation of water vapor diffusion requires assessment of the potential of nuclear waste repositories (Spycher et al. 2003; Saito et al. 2006).

The online version of the original article can be found under doi:10.1007/s11242-008-9267-z.

J. D. Jabro $(\bowtie)$

Northern Plains Agricultural Research Laboratory, USDA-ARS, 1500 N. Central Avenue, 59270 Sidney, MT, USA

e-mail: jay.jabro@ars.usda.gov 


\section{Reference}

Saito, H., Simunek, J., Mohanty, B.P.: Numerical analysis of coupled water, vapor, and heat transport in the vadose zone. Vadose Zone Journal 5, 784-800 (2006) 